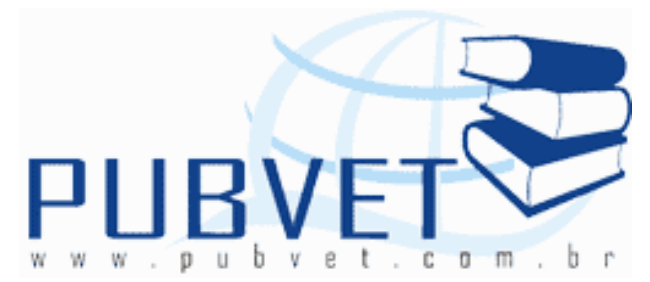

PUBVET, Publicações em Medicina Veterinária e Zootecnia.

\title{
Pesquisa sorológica do parvovirus suíno em reprodutoras de rebanhos suínos da Bahia
}

\author{
Isa Maria Sousa Trindade ${ }^{1}$, Gubio Soares Campos $^{1}$, Rita de Cassia Pimentel ${ }^{1}$, \\ Jose Carlos de Andrade Moura', Silvia Ines Sardi*
}

\begin{abstract}
${ }^{1}$ Laboratório de Virologia, Instituto de Ciências da Saúde, Universidade Federal da Bahia, Bahia, Brasil.

•Escola de Medicina Veterinária, Universidade Federal da Bahia, Bahia, Brasil

* Autor para correspondência: Laboratório de Virologia 2 andar. Departamento de Bio- interação, Instituto de Ciências da Saúde, Universidade Federal da Bahia. Av. Reitor Miguel Calmom s/n- Vale do Canela- CEP 40110-100, Salvador - Bahia. Tel./Fax: (71)3235-0937. E-mail: sissardi@yahoo.com.br.
\end{abstract}

\section{Resumo}

Parvovírus suíno ( $P P V$ ) provoca importantes perdas econômicas em suínos decorrentes de problemas reprodutivos como morte fetal, mumificação ou aborto. Vários estudos sorológicos ou de incidência do PPV foram realizados em vários estados do Brasil, mas não há informações sobre a ocorrência do $P P V$ nos rebanhos suínos do estado da Bahia. O objetivo deste trabalho foi pesquisar a resposta imune para o $P P V$ durante a vida reprodutiva das fêmeas suínas. O estudo foi realizado em onze fazendas escolhidas aleatoriamente (com ou sem vacinação) de diferentes regiões da Bahia. Os animais em estudo foram reprodutoras $(n=221)$ em lactação entre 10 meses a 5 anos de idade. 
Amostras de sangue foram coletadas de reprodutoras vacinadas ou sem vacinar para determinar os níveis de anticorpos contra o PPV através da técnica de inibição da hemaglutinação $(\mathrm{HI})$. Os resultados mostraram que 94,12\% (208/221) do total das reprodutoras em estudo tinham títulos protetores de anticorpos ( $\geq 1: 80$ ). Nas fêmeas de rebanhos sem vacinar os títulos HI foram desde 1:195 até 1: 48.488. Nas fazendas que vacinam foi encontrado que $56,11 \%$ das fêmeas tinham títulos $\mathrm{HI} \geq 1$ : 2560 . O analise da resposta imune depois de varias doses de vacina nestes rebanhos demonstra que múltiplas vacinações pós-parto podem bloquear a resposta imunológica. Destes resultados surge que PPV está circulando nos rebanhos suínos da Bahia e que segundo os títulos HI detectados, as reprodutoras destes rebanhos vacinados ou não, estariam protegidas contra a infecção viral.

Palavras-chave: Parvovírus suíno, anticorpos, imunidade, vacinas.

\title{
Serological survey of porcine parvovirus in sows from swine herds of Bahia
}

\begin{abstract}
Porcine parvovirus (PPV) causes extensive prenatal losses in swine characterized by foetal death, mummification and abortion. There are several studies concerning to serological surveys of PPV in many states of the Brazil, but there is no information about the state of Bahia. Therefore, the aim of this work was to investigate the anti-PPV immune response in breeding sows from different herds of Bahia. The study was carried on in eleven randomly chosen farms (with and without vaccination) in the state of Bahia. The animals on trial were female pigs $(n=221)$ in lactation between 10 months to 5 years old. Blood samples were taken to determine the levels of antibodies against the $P P V$ in the herds by the haemagglutination inhibition (HI) test. The results showed that $94,12 \%(208 / 221)$ of the sows had protective HI-titers $(\geq 1: 80)$. In naturally infected herds the HI-titers in the sows were from 1:195 to 1 : 48.488. In the vaccinated herds HI-titers of $\geq 1: 2560$ were found in $56,11 \%$ of
\end{abstract}


the sows. It was also analyzed in these herds the immune response at several doses of vaccine and it was found that continuous vaccination after postpartum may block the immune response. The findings indicate that PPV is circulating in the pig herds of Bahia and as the HI-titer revealed most of the breeding sows, vaccinated or not, are protected against the viral infection.

\section{INTRODUÇÃO}

A Parvovirose suína, causada pelo Parvovírus Suíno (PPV) é uma doença de distribuição universal e de alta prevalência (MURPHY et al., 1999; MENGELING et al., 2006). O PPV foi associado pela primeira vez a distúrbios reprodutivos na Inglaterra após seu isolamento de natimortos e restos de aborto (envoltórios fetais) (CARTWRIGHT \& HUCK, 1967). A infecção viral ocorre principalmente pelo contato oro-nasal com fezes e secreções contaminadas e o sintoma característico da doença é a ocorrência de fetos natimortos e mumificados em diferentes estágios de desenvolvimento, principalmente quando as fêmeas suínas são infectadas durante a primeira metade da gestação (MURPHY et al., 1999; SOBESTIANSKY et al., 1999; MENGELIN et al., 2000, MUZYCZKA \& BERNS, 2002). A semelhança de sintomas reprodutivos entre várias doenças que atingem os suínos, faz com que apenas o exame clínico não seja suficiente para determinar a causa do transtorno e sim a realização de exames laboratoriais específicos.

A primeira pesquisa na América Latina relacionada ao PPV foi em Minas Gerais, onde foram encontrados $55,3 \%$ de animais soropositivos para o agente (GOUVEIA, 1982). Desde então, varias pesquisas da prevalência do PPV foram realizadas em diversas regiões do Brasil, mas até o momento, são poucos os estudos relacionados ao agente na região Nordeste (GOUVEIA et al, 1984; DAMBRÓs et al.,1994; BERSANO et al,. 2000; RODRÍGUEZ et al.,2003).

A prevalência do $P P V$ no país levou a utilizar vacinas inativadas que promovem uma resposta imune protetora para a infecção viral. Sugere-se que títulos antiPPV de 1:80 são considerados protetores (PREM \& MENGELING 1998; 
BARCELLOS et al., 1998; SOBESTIANSKY et al., 1999). No Estado da Bahia, a vacinação contra $P P V$ vem acontecendo em alguns rebanhos, porém nota-se a falta de estudos desta doença que afeta o setor. O PPV é um vírus endêmico na maior parte do pais e acreditamos que os rebanhos suínos da Bahia não escapam a esta condição. Esta pesquisa é um trabalho inédito sobre este agente nos rebanhos suínos da Bahia que revelará alguns aspectos da situação atual da Parvoviroses suina, principalmente em fêmeas em reprodução, categoria alvo desta doença. Este trabalho aborda uma pesquisa sorológica do $P P V$ em fêmeas reprodutoras de rebanhos naturalmente infectados e investiga em rebanhos que vacinam a cinética da resposta imune vacinal.

\section{MATERIAIS E MÉTODOS}

\section{Cultivo de células e Produção de virus}

Os ensaios para a multiplicação e produção do PPV (cepa NADL) foram utilizadas monocamadas confluentes de células de rim suíno PK15 (Porcine Kidney Cell -American Type Cell Culture-ATCC) (cedidas pela Dra. Zélia Lobato, da Escola de Medicina Veterinária- UFMG).

As células PK15 foram mantidas em meio Minimum Essential Medium (Mem-E) suplementado com $10 \%$ de soro fetal bovino e para o repique celular foi utilizada a técnica de desagregação enzimática com Tripsina 0,25\% (GIBCO.Co, USA). A infeç̧ão das células PK15 com PPV-NADL foi feita simultaneamente ao repique celular a uma multiplicidade de infeç̧ão $=0,5$ (MOI). Após observação do efeito citopático, as culturas de células infectadas foram congeladas e descongeladas e o material centrifugado a 10000 RPM por 15 minutos a $10^{\circ} \mathrm{C}$ para conservação de sobrenadante. O sobrenadante viral teve um titulo de 64 Unidades Hemoaglutinantes (UHA) (JOO et al., 1976).

\section{Animais}

$\mathrm{Na}$ realização destes experimentos foram utilizadas fêmeas suínas $(n=221)$ em idade reprodutiva, entre oito meses e cinco anos de idade, das linhagens 
Naima e Camborough 22, em fase de gestação ou lactação, criadas em regime de confinamento. Estes animais eram provenientes de 11 granjas com e sem vacinação contra $P P V$, situadas em 11 municípios diferentes do Estado da Bahia. A amostragem de cada granja representa cerca de $10 \%$ da quantidade total de animais do rebanho.

A vacina utilizada pelas granjas para imunização dos rebanhos foi do tipo polivalente inativada, contendo Parvovírus suíno, Leptospira pomona, L. grippotyphosa, L. canicola, L. icterohaemorrhagiae, L. bratislava, L. hardjo e Erysipelotrix Rhusiopathiae, aplicada na dose de $3 \mathrm{ml}$ segundo as indicações do fabricante. O esquema vacinal aplicado nas granjas para as fêmeas começa aos 180 dias de idade, e a segunda dose aos 21 dias após esta primovacinação. As revacinações são repetidas 15 dias após cada parto.

Fêmeas que possuíam registro clínico detalhado $(n=181)$ foram selecionadas para estudos comparativos da relação entre títulos de anticorpos anti-PPV e problemas reprodutivos.

\section{Coleta de Amostras}

As amostras de sangue, realizadas por punção da veia cava, foram deixadas a temperatura ambiente ate formação do coagulo e logo depois centrifugadas a 3000 RPM durante 10 minutos para obtenção do soro. Estes soros foram armazenados e congelados a $-20^{\circ} \mathrm{C}$, até o momento do uso.

\section{Inibição da Hemoaglutinação: Detecção e titulação de anticorpos anti-PPV}

Os soros foram primeiramente incubados em banho-maria a $56^{\circ} \mathrm{C}$ por 30 minutos para inativação do complemento e logo depois para eliminar substancias inibidoras inespecíficas da hemoaglutinação foram submetidos a uma incubação com uma solução de caolim a $25 \%$ (P/V) e solução de hemácias de cobaios a $30 \%$ em PBS (V/V). Posteriormente, o soro centrifugado a 3000 RPM por 10 minutos, foi utilizado para a deteç̧ão e titulação de anticorpos através do teste de Inibição da Hemoaglutinação 
segundo o descrito por $J 00$ et al., 1976. O título de anticorpos foi expresso como a mais alta diluição em que a hemoaglutinação foi inibida.

\section{ANÁLISE ESTATÍSTICA}

Este trabalho foi analisado com o programa SPSS-Statistical Package Social Science, V.12.0, utilizando o teste Mann- Whitney para distribuições não paramétricas $(p>0,05)$.

\section{RESULTADOS}

\section{AMOSTRAGEM DAS FÊMEAS EM IDADE REPRODUTIVA}

As características da população em estudo são mostradas na Figura 1. Observa-se que 48,68\% (107/221) das fêmeas em estudo eram jovens com uma media de idade entre um e dois anos. A pesquisa de anticorpos nas fêmeas mostra que $98,34 \%(217 / 221)$ desta população tinham anticorpos para $P P V$.

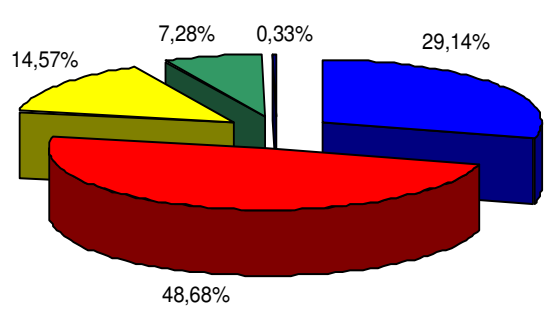

$\mathbf{\square}<1$ ano $\square 1,1-2$ anos $\square 2,1-3$ anos $\square 3,1$ - 4 anos $\mathbf{\square}>4,1$ anos

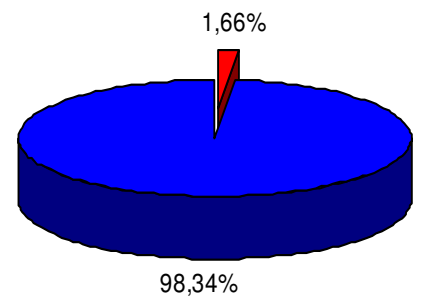

$\square$ Amostras negativas $\quad$ Amostras positivas

Figura 1: Características da população em estudo

\section{TITULAÇÃO DE ANTICORPOS PARA PPV NAS FÊMEAS REPRODUTORAS}

O Quadro 1, mostra a distribuição de freqüências de títulos de anticorpos anti$P P V$ nos rebanhos analisados. 
TRINDADE, I.M.S. et al. Pesquisa sorológica do parvovirus suíno em reprodutoras de rebanhos suínos da Bahia. PUBVET, Londrina, V. 5, N. 25, Ed. 172, Art. 1164, 2011.

Quadro 1: Distribuição da freqüência de anticorpos anti-PPV encontrados em 221 amostras de reprodutoras suínas oriundas de rebanhos localizados em 11 municípios da Bahia.

\begin{tabular}{|c|c|c|c|c|c|c|c|c|}
\hline GRANJA & $\mathbf{N}$ & $<5$ & 5 a 40 & $\begin{array}{c}80 a \\
320\end{array}$ & $\begin{array}{l}640 \mathrm{a} \\
1.280\end{array}$ & $\begin{array}{c}2.560 \\
a \\
10.000\end{array}$ & $\begin{array}{c}>10.00 \\
0\end{array}$ & $\begin{array}{l}\text { VALOR } \\
\text { MÉDIO }\end{array}$ \\
\hline G1 & 13 & - & - & 1 & - & 10 & 2 & 12.333 \\
\hline G2 & 32 & - & - & 4 & 6 & 20 & 2 & 3.261 \\
\hline G3 & 20 & - & - & 1 & 12 & 5 & 2 & 1.311 \\
\hline G4 & 21 & - & - & - & 2 & 14 & 5 & 8.282 \\
\hline G5 & 9 & - & - & - & 2 & 7 & - & 3.738 \\
\hline G6 & 9 & - & - & - & 4 & 4 & 1 & 3.754 \\
\hline G7 & 13 & - & - & - & - & 6 & 7 & 16.000 \\
\hline G8 & 11 & - & - & - & 5 & 5 & 1 & 5.229 \\
\hline G9 & 30 & - & 1 & 25 & 1 & 3 & - & 553 \\
\hline G10 & 30 & - & - & - & 1 & 5 & 24 & 48.488 \\
\hline G11 & 33 & 5 & 7 & 19 & 1 & 1 & - & 195 \\
\hline $\begin{array}{c}\text { TOTAL } \\
(\%)\end{array}$ & 221 & $\begin{array}{r}5 \\
(2,26)\end{array}$ & $\begin{array}{r}8 \\
(3,62)\end{array}$ & $\begin{array}{r}\mathbf{5 0} \\
(22,63)\end{array}$ & $\begin{array}{r}34 \\
(15,38)\end{array}$ & $\begin{array}{r}80 \\
(36,2)\end{array}$ & $\begin{array}{r}44 \\
(19,91)\end{array}$ & - \\
\hline
\end{tabular}

$\mathrm{n}=$ número de soros

G1-G8: Granjas que vacinam G9-G11: Granjas sem vacinação.

Títulos $>1: 5$ são considerados positivos para $P P V$.

Títulos $\geq 1: 80$ são considerados protetores para $P P V$.

Este quadro mostra que 56,11\%(124/221) das fêmeas apresentaram títulos acima de $2.560 ; 22,63 \%(50 / 221)$ entre 80 e $320 ; 15,38 \%(34 / 221)$ entre 640 e $1.280 ; 3,62 \%(8 / 221)$ entre cinco e $40 ;$ e $2,26 \%(5 / 221)$ soronegativos para o $P P V$.

Todas as reprodutoras vacinadas alcançaram títulos acima do valor protetor (>1:80), mostrando que $71,09 \%(91 / 128)$ tiveram títulos anti-PPV de $\geq$ $1: 2560$. Dentre as granjas vacinadas pode-se observar que as fêmeas das $G 1$ e G7, possuem maiores valores nos títulos de anticorpos 1:12. 333 e 1:16.000 respectivamente. A G4 e G8, níveis intermediários de 1:8.282 e 1:5.229, respectivamente. Outras três granjas, as G2, G5 e G6 apresentam títulos 
semelhantes entre si, de aproximadamente 1:3.000. Finalmente, encontramos o nível mais baixo na G3 cujas fêmeas possuíam em media títulos anti-PPV de 1:1. 311.

Nas três granjas que não vacinam, foram encontrados títulos com amplas variações, observando-se títulos anti-PPV desde 1:195 na G11, 1:553 na G9 até o valor mais alto $1: 48.488$, na G 10 .

\section{PERFIL SOROLOGICO DE ANTICORPOS ANTI-PPV EM REPRODUTORAS VACINADAS.}

A Figura 2 apresenta a cinética da resposta imune vacinal em reprodutoras segundo o numero de doses recebidas. Observa-se que nos diferentes grupos de reprodutoras já desde a segunda dose da vacina inativada os títulos são acima do valor protetor $1: 80$.

Neste ensaio grupos de femeas $(n=5)$, foram separadas de acordo as dose recebidas. Na G2 os grupos mostran que na terceira imunização o título antiPPV alcança valores de 1:320, na quarta imunização chega a 1:1280, aumentando ligeramente na quinta e sexta dose ate um valor maximo de $1: 2560$. Na G3 os grupos mostram que o título anti-PPV teve poucas variações desde a segunda dose com valores de 1:640, chegando ao maximo de 1:1280. Nas fêmeas da G4 destaca-se que na terceira dose os valores médios são acima de 1:2560, mas o nivel de anticorpos continua a aumentar ate na quinta dose chegar a valores de 1:20. 000. Porém ao receber a sexta dose os títulos desceram a 1:8.000. 


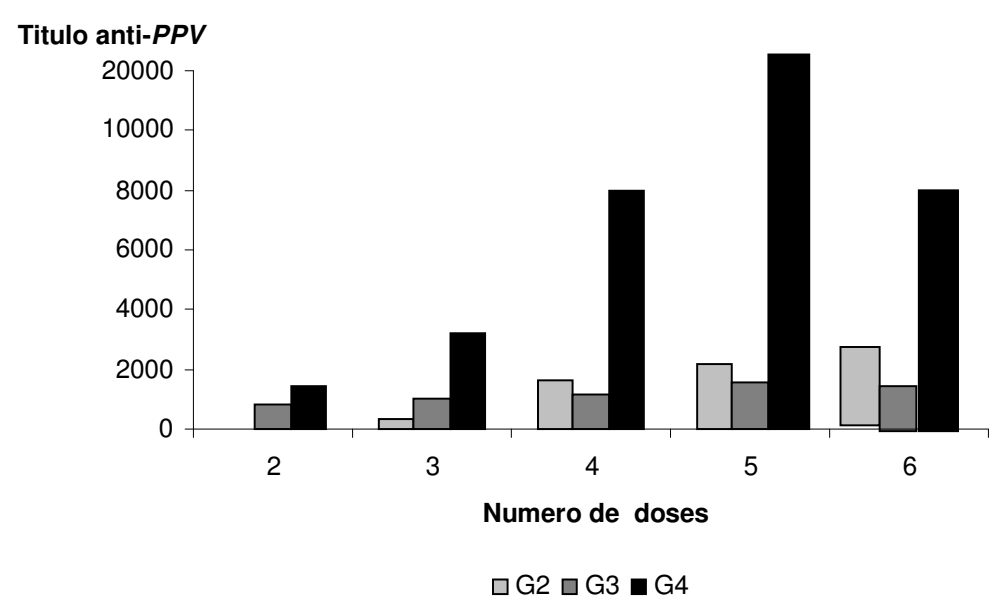

Figura 2: Perfil sorológico de anticorpos anti-PPV em reprodutoras vacinadas oriundas de três granjas diferentes

\section{PERFIL SOROLÓGICO DE ANTICORPOS ANTI-PPV EM REPRODUTORAS NOS REBANHOS SUINOS NÃO VACINADOS.}

A Figura 3 mostra o perfil sorológico de fêmeas entre 1 e 2 anos de idade de três granjas que nunca vacinaram contra PPV (G10 e G11). O título de anticorpos aumenta de acordo com o número de partos que a fêmeas tiveram. Nota-se em ambos os grupos que as fêmeas tiveram um aumento do título anti-PPV no momento do $2^{\circ}$ parto. Os títulos anti-PPV alcançaram valores de até 1:32. 000 para G10, enquanto que na G 11 alcançaram no máximo 1:129 

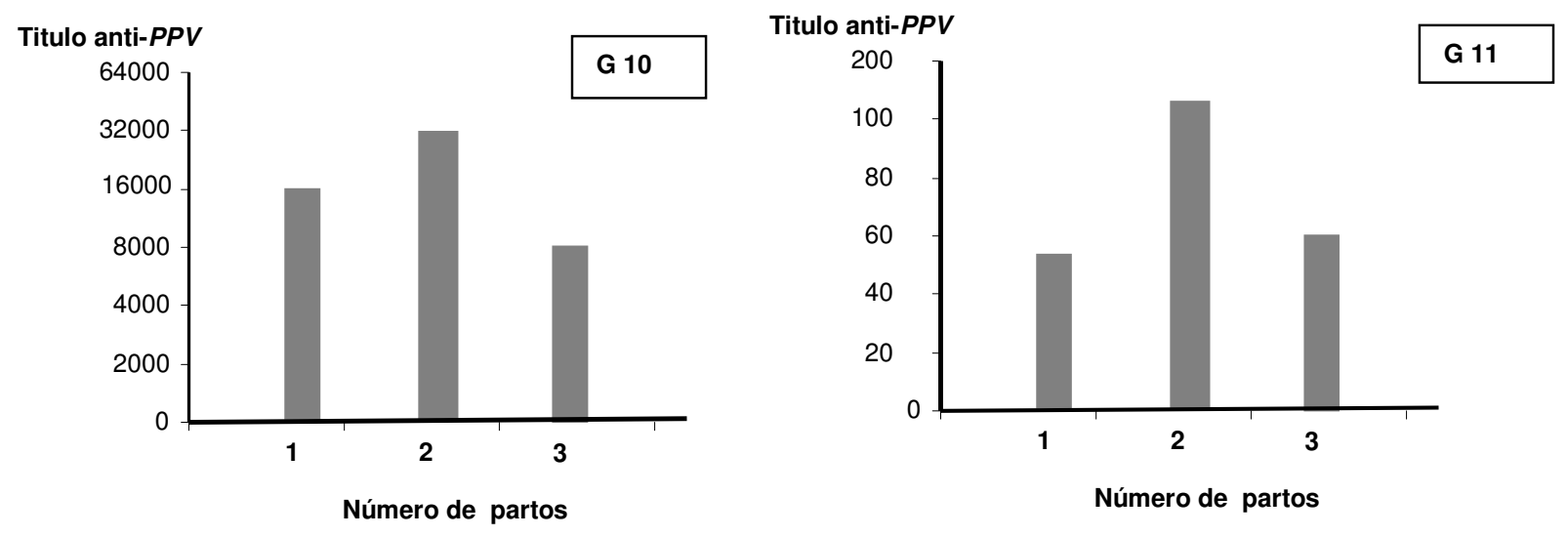

Figura 3: Perfil sorológico de anticorpos anti-PPV em fêmeas suínas naturalmente infectadas segundo numero de partos

\section{RESPOSTA IMUNE VACINAL EM PRESENÇA DE ALTOS NIVEIS DE ANTICORPOS ANTI-PPV}

A Figura 4 mostra a resposta imune de reprodutoras vacinadas ( $G$ 4) ao receber uma nova dose de vacina em presença de altos títulos anti-PPV.

A figura mostra que um grupo de fêmeas vacinadas após receber a quarta dose de vacina, foram divididos em dois subgrupos $A(n=4)$ e $B(n=2)$. Ambos os grupos apresentaram um aumento do nível dos títulos anti-PPV até os 90 dias. O título anti-PPV no grupo A no dia 120 era de aproximadamente 1:20. 000, e no dia 220, final do experimento, chegou a 1:35.000.

No grupo B, no dia 120, momento de receber uma nova dose o título de anticorpos anti-PPV era de 1:20. 000, valor que continuo com poucas variações até o final do ensaio.

O teste de Mann - Whitney para distribuições não paramétricas usado para comparação entre os grupos dentro do mesmo tempo demonstrou não haver diferença significativa entre os dois grupos ( $p>0,05)$, exceto no tempo de 120 dias, onde houve diferença significativa entre os grupos $(p<0,05)$. 
Titulos anti PPV1:

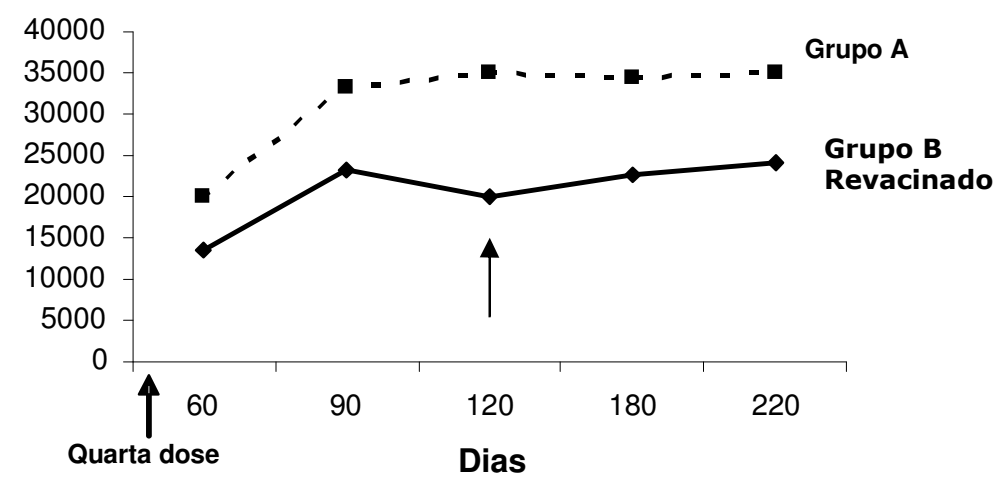

Figura 4: Resposta imune de reprodutoras suínas ao receber uma dose de vacina em presença de altos títulos anti-PPV

\section{RELAÇÃo ENTRE TÍtULOS DE ANTICORPOS CONTRA PPV E PROBLEMAS REPRODUTIVOS}

Neste estudo foram utilizados 181 fêmeas que possuíam ficha de registro clínico. A maioria destes animais, 63,25 \% (128/181), tinha de 1 a 4 anos de idade na época da colheita.

No Quadro 2 são descritos os problemas reprodutivos relatados nos animais e suas respectivas freqüências. Verifica-se que entre as fêmeas vacinadas com problemas reprodutivos foram encontrados altos níveis de anticorpos contra PPV. As G1, G4 e G8 apresentaram títulos acima de 10.000, as G2 e G5, títulos em torno de 2.000, e a G3 um nível mais baixo, 993.

Neste quadro, observa-se que as maiores porcentagens de problemas reprodutivos, 44 e 42,85 \%, na G1 e G4 respectivamente apresentaram os mais altos títulos de anticorpos contra o agente, de até 1:15. 000.

$\mathrm{Na}$ G11, granja naturalmente infectada, reportou como único problema reprodutivo nas fêmeas a presença de natimortos e mostrou o título anti-PPV mais baixo $(1: 150)$. 
TRINDADE, I.M.S. et al. Pesquisa sorológica do parvovirus suíno em reprodutoras de rebanhos suínos da Bahia. PUBVET, Londrina, V. 5, N. 25, Ed. 172, Art. 1164, 2011.

Quadro 2: Relação entre títulos de anticorpos anti-PPV e problemas reprodutivos em fêmeas de sete granjas com registro de histórico clínico

\begin{tabular}{|c|c|c|c|c|c|c|c|c|c|}
\hline \multirow[t]{2}{*}{ GRANJA } & \multirow{2}{*}{$\begin{array}{c}\text { SOROS } \\
\text { (n) }\end{array}$} & \multirow{2}{*}{$\begin{array}{l}\text { ANIMAIS COM } \\
\text { PROBLEMAS } \\
\text { REPRODUTIV. } \\
(\mathbf{\% )}\end{array}$} & \multirow{2}{*}{$\begin{array}{l}\text { TÍTULO } \\
\text { ANTI-PPV }\end{array}$} & \multicolumn{6}{|c|}{ PROBLEMA REPRODUTIVO } \\
\hline & & & & $\mathbf{A}$ & MM & MN & NM & PP & RC \\
\hline G1 & 25 & $11(44 \%)$ & $1: 15.000$ & 42,86 & 21,43 & - & - & 7,14 & 28,57 \\
\hline G2 & 32 & $13(40,62 \%)$ & $1: 2.021$ & 30,77 & - & - & - & - & 69,23 \\
\hline G3 & 20 & $7(35 \%)$ & $1: 993$ & 25 & - & - & - & - & 75 \\
\hline G4 & 21 & $9(42,85 \%)$ & $1: 14.222$ & 10,53 & 21,05 & - & 36,84 & 5,26 & 26,32 \\
\hline G5 & 25 & $2(8 \%)$ & $1: 2.500$ & 50 & - & - & - & - & 50 \\
\hline G8 & 25 & $4(16 \%)$ & $1: 10.250$ & - & - & - & - & 20 & 80 \\
\hline G11 & 33 & $4(12,12 \%)$ & $1: 150$ & - & - & 100 & - & - & \\
\hline
\end{tabular}

G1-G8: Granjas com vacinação; G11: Granja sem vacinação.

$A=$ abortos $; M M=$ fetos mumificados; $M N=$ morte neonatal $; M=$ natimortalidade;

$\mathrm{PP}=$ parto prematuro; $\mathrm{RC}=$ retorno ao cio.

\section{DISCUSSÃO}

A suinocultura é uma exploração cujo rendimento econômico depende basicamente da capacidade de reprodução das matrizes. Portanto, aqueles agentes que causam alterações na capacidade reprodutiva dos animais, como o PPV, merecem especial atenção (GARDNER et al., 1996; AMARAL et al., 2000; MENGELIN et al., 2000).

A pesquisa sorológica do $P P V$ nas regiões mais desenvolvidas da suinocultura baiana demostrou que $98,34 \%$ das fêmeas reprodutoras foram soropositivas para PPV.

A pesquisa de anticorpos em rebanhos suínos não vacinados mostrou que 0 vírus esta circulando ativamente no campo. Os elevados títulos anti-PPV em algumas propriedades confirmam a alta circulação do vírus no rebanho, no entanto os títulos menores também encontrados confirmam a presença viral porem, com um grau de infecção menor. Outro achado nestes rebanhos foi o aumento nos títulos de anticorpos entre $01^{\circ}$ e $2^{\circ}$ parto nas reprodutoras. 
Alguns autores mencionam que este fato ocorre na maioria das matrizes, entre o $1^{\circ}$ e $\circ 2^{\circ}$ parto, porque entram em contato com o agente viral através dos animais mais velhos ou pelas instalações contaminadas, aumentando assim a proteção natural contra o vírus (SOBESTIANSKY et al., 1999).

Por outra parte, a pesquisa realizada nos rebanhos de granjas que aderem a uma vacinação rotineira contra $P P V$, verificaram-se títulos de anticorpos anti$P P V$ de valores maiores ao considerados protetores pela literatura (1:80) (BROWN et al., 1987; LOBATO, 1990; PREM \& MENGUELIN, 1998; BARCELLOS et al., 1998; SOBESTIANSKY et al., 1999). A resposta imune encontrada entre os oito rebanhos vacinados foi heterogênea, mas considera-se que variáveis no manejo alimentar e/ou sanitário, de cada rebanho ou o contato com o vírus circulante a campo, acabam refletindo na resposta imunológica do animal (ORAVAINEN et al., 2005).

De forma inédita nos estudos sobre $P P V$, este trabalho analisou a cinética da resposta imune para cada dose de vacina recebida. Assim, foi mostrado que o nível de anticorpos gerados desde a segunda dose de vacina, alcançou títulos protetores. Os títulos de anticorpos vão aumentando conforme ao número de vacinações, em função da memória imunológica gerada após vacinações repetidas. Mas foi observado que o nível de anticorpos depois de repetidas doses se mantém estável ou pode inclusive diminuir. Possivelmente, isto é uma consequência da saturação da resposta imune, evento que acontece em decorrência de repetidos e curtos espaços entre os estímulos antigênicos (15 dias após cada parto), fenômeno conhecido também como "paralisia imunológica" (MARGNI, 1996). A confirmação desta hipótese ficou demostrado quando em presença de altos níveis de anticorpos

(1:20. 000), à aplicação de novas imunizações não apresenta vantagens e inclusive prejudica a resposta imune obtida; o novo estímulo antigênico é bloqueado pelos anticorpos ainda circulantes no sangue, o que diminui o nível sérico dos anticorpos.

Estes resultados postulam a hipótese de que revacinações num curto período de tempo e de forma sucessiva podem se tornar desnecessárias. Os níveis de 
anticorpos anti-PPV alcançados após três ou quatro doses seguindo este esquema vacinal pós-parto e o contato com o vírus que circula a campo provavelmente seriam suficientes para manter nestes rebanhos uma estimulação antigênica adequada para estar protegidos da infecção viral.

Outro interesse desta pesquisa foi investigar os problemas reprodutivos declarados nestes rebanhos (natimortos, retorno ao cio, etc.). Nos rebanhos encontramos fêmeas com altos títulos anti- $P P V$, entretanto com problemas reprodutivos. Sendo assim, com base nos achados dos títulos de anticorpos contra $P P V$, acreditamos que os problemas reprodutivos estariam acontecendo por outras causas. Pesquisas recentes mostram que é baixa a frequência de isolamento de $P P V$ de rebanhos a partir de fetos natimortos e mumificados de amostras provenientes de diversas regiões do Brasil inclusive da Bahia (PESCADOR et al., 2007; ROCHA et al., 2010). Possivelmente, a ampla difusão do uso de vacinas para controle da infecção viral sugere que esta forma de prevenção para os problemas reprodutivos associados ao PPV no país, está sendo realmente efetiva (FERNANDEZ et al., 2003; MENGELIN, 2006).

De modo geral, se sugere que o PPV circula nos rebanhos suínos da Bahia como mostrado nos rebanhos soropositivos por infecção natural. A circulação do vírus a campo e as imunizações efetuadas nestes rebanhos despertaram uma resposta imune humoral acima dos títulos anti-PPV considerados protetores para à infecção viral. Sendo assim, o controle do PPV através de programas de vacinação continua a ser uma ferramenta importante, entretanto o esquema vacinal aqui praticado repetindo a dose a cada parto é questionado. Porém, mais estudos são necessários para esclarecer alguns aspectos da resposta imune contra $P P V$.

\section{REFERÊNCIAS BIBLIOGRÁFICAS}

1. AMARAL, A. L.; MORÉS, N.; BARIONI JR. W. WENTZ, I.; BORTOLOZZO, F.P.; SOBESTIANSKY, J.; DALLA COSTA, O. A. Fatores de risco associados ao desempenho reprodutivo da fêmea suína. Arq. Med. Vet. Zootec. Belo Horizonte, v.52, n.5, p.479-486, 2000. 
2. BARCELLOS, D.E.S.N.; SOBESTIANSKY, J.; PIFFER, I. A. Utilização de Vacinas. In: SOBESTIANSKY, J.; WENTZ, I.; SILVEIRA, P.R.S.; SESTI, L.A.C. Suinocultura Intensiva. $1^{a}$ ed. Concórdia-SC: Embrapa Suínos e Aves.388 p.p.237-253. 1998

3. BERSANO, J.G.; VILLALOBOS, E.M.C.; SOUZA, M.C.C; GÓES,A.C. Emprego da Reação de Inibição da hemoaglutinação (HI) e do ELISA test no diagnóstico do Parvovírus suíno (PPV) no Estado de São Paulo. In: Reunião Anual do Instituto Biológico, 2000, São Paulo. Arq. Inst. Biol. v. 67. p. 41, 2000.

4. BLOOM, M.E.; YOUNG, N.S. Parvoviruses. In: KNIPE, D. M.; HOWLEY, P.M. Fields Virology. 4. ed. Philadelphia: Lippincott Williams \& Wilkins, 3087 p. p.2361-2379.2002

5. BROWN, T.T.Jr.; WHITACRE,M.D.;ROBISON,W. Use of an inactived vaccine for prevention of parvovirus-indeced reproductive failure in gilts. J. Am. Vet. Med. Assoc. v.190, n. 2, p.179$182,1987$.

6. CARTWRIGHT, S.F.; HUCK, R.A. Viruses isolated in association with herd infertility, abortions and stillbirths in pigs. Vet. Rec. v.81, n.8, p. 196-197, 1967.

7. DAMBRÓS, R.M.F.; MARQUES, J.L.L., JAENISCH, F.R.F. Demonstrativo Sorológico para o Parvovírus Suíno no Estado de Santa Catarina no ano de 1994. In: VII CONGRESSO BRASILEIRO DE VETERINÁRIOS ESPECIALISTAS EM SUÍNOS, 7, 1995, Blumenau-SC. Anais: ABRAVES, p. 151, 1995

8. FERNANDES, L.T.; CIACCI-ZANNELLA, J.R.; TROMBETTA, C.; SOBESTIANSKY,J.; OLIVEIRA, S.; BRITO, L.A.B. Avaliação da Patogenicidade do Circovírus Suíno tipo 2 (PCV2) isolado no Estado de Santa Catarina através de coinfecção experimental com Parvovírus Suíno.In:XI CONGRESSO BRASILEIRO DE VETERINÁRIOS ESPECIALISTAS EM SUÍNOS, 11, 2003, GoiâniaGO.Anais: ABRAVES, p.89-90, 2003

9. GARDNER, I.A. ; CARPENTER, T.E.; LEONTIDES, L.; PARSONS, T.D. Financial evaluation of vaccination and testing alternatives for control of parvovirus-induced reproductive failure in swine. J. Am. Vet. Med. Assoc. v. 208, n.6, p.863-869, 1996.

10. GOUVEIA,A.M.G.; GOMEZ,M.C.; REIS,R.Alterações Reprodutivas e Prevalência de Anticorpos Inibidores da Hemoaglutinação para o parvovírus suíno no Estado de Minas Gerais. Pesq. Vet. Bras. v.4, n.1, p.17-22,1984.

11. GOUVEIA, A.M.G. Alterações Reprodutivas e Prevalência de Anticorpos Inibidores da Hemoaglutinação para o parvovírus suíno no Estado de Minas Gerais. Belo Horizonte, 1982. 58 p.Tese (mestrado)-Universidade Federal de Minas Gerais,1982.

12. JOO, H.S.; DONALDSON-WOOD, C.R.; JOHNSON, R.H. A Standartised haemaglutination inhibition test for porcine parvovirus antibody .Aust. Vet. J. v.52, n.9, p.422-424, 1976 a.

13. KRZYZANIAK, E.L.; GOTTSCHALK, A. F.; MODOLO, J.R.; PADOVANI, C.R.; KIECKHOFER, H.; VISENTINI, P.R.S. Avaliação da mobilização e distribuição temporal e espacial de focos de parvovirose suína no Estado de São Paulo. A Hora Veterinária Ano 21, n.126, 2002.

14. LOBATO, Z.I.P .Avaliação da Resposta Sorológica de Suínos Imunizados contra o Parvovírus Suíno com uma Vacina Inativada Experimental e pelo Método de "Feed Back" (Retroinfecção). Belo Horizonte, 1990. 90p. Tese (mestrado) - Universidade Federal de Minas Gerais ,1990. 
15. MARGNI, R.A. Inmunología e Inmunoquímica - Fundamentos. 5.ed.Buenos Aires: Ed.Médica Panamericana, 1996. 976p.Cap.:15. Respuesta inmune humoral. p. 278-295.

16. MENGELING, W.L; GUTEKUNST, D.E; PIRTLE, E.C. Antibody Response of Pigs to Inativated Monovalente and Bivalente vaccines for Porcine Parvovirus and Pseudorabies Virus. Am. J. Vet. Res. v.41, n.10, p. 1569-1571, 1980.

17. MENGELING, W. L; LAGER, K. M.; and VORWALD. The effect of porcine parvovirus and porcine reproductive and respiratory syndrome virus on porcine reproductive performance. Anim. Reprod. Sci. v. 60-61, p.199-210, 2000.

18. MENGELIN W.L. Porcine parvovirus In: STRAW, B; DÀLLAIRE, S., TAYLOR D., ZIMMERAMAN, J (Edits) Diseases of swine. Ames, Iowa: Iowa State of University Press. 2006, p. 378-385

19. MURPHY, F. A.; GIBBS, E.P.J.;HORZINEK, M.C. and STUDDERT, M.J. Veterinary Virology.3. ed. USA: Academic Press, 1999. 629p. Cap.:21. Parvoviridae. p. 343-355.

20. MUZYCZKA, N.; BERNS, K.I. Parvoviridae: the viruses and their replication. In: KNIPE, D. M.; HOWLEY, P.M. Fields Virology 4. ed., Philadelphia: Lippincott Williams \& Wilkins, 2002. 3087p., p. 2327-2359.

21. ORAVAINEN, J.; HEINONEN, M.; TAST, A.; VIROLAINEN, J.V.; PELTONIEMI. O. High porcine parvovirus antibodies in sow herds prevalence and associated factors. Reprod. Dom. Anim. v.40, n.1, p. 57-61, 2005.

22. PREM, S. P.; MENGELING, W. L. Parvovirosis Porcina: Características Generales. Porcinos- Aula Veterinária, Madrid, n.46. p.13-25, 1998.

23. PESCADOR, C. R BANDARRA,P., CASTRO L.,ANONIASSI, N.A.B., RAVAZZOLO A.P., SONNE L., CRUZ C.E.F., DRIEMEIER D. Co-infection by porcine circovirus type 2 and porcine parvovirus in aborted fetuses and stillborn pigltes in Southern Brazil. Pesquisa Veterinária Brasileria v.27 n.10, p425-429, 2007.

24. RODRIGUES, C.A.R.; HOMEM, V.S.F.; HEINEMANN, M.B.; FERREIRA NETO, J.S.; RICHTZENHAIN, L.J. ; SOARES, R.M. Soroprevalência de Anticorpos anti-parvovírus suíno em suínos do município de Uruará, estado do Pará. Arq. Inst. Biol. São Paulo, v.70, n.4, p.501503, 2003.

25. ROCHA , D.L., ALBERTONI, G.C., SANTOS J.L. Identificação do Circovirus suíno tipo 2 e do Parvovirus suíno em fetos suínos natimortos e mumificados provenientes de granjas no Brasil., Ci.Anim.Bras.Gôiania V.11, n.3, p 600-606, 2010.

26. SOBESTIANSKY, J.; MORES, N.; ROEHE, P. M. Parvovirose suína. Suinocultura Dinâmica. Ano 7. n.21, p. 1-5, 1999. 